\title{
Btbd3 expression regulates compulsive-like and exploratory behaviors in mice
}

\author{
Summer L. Thompson ${ }^{1,2}$, Amanda C. Welch', Emily V. Ho ${ }^{1}$, João M. Bessa ${ }^{3,4}$, Carlos Portugal-Nunes ${ }^{3,4}$, Mónica Morais ${ }^{3,4}$,
} Jared W. Young', James A. Knowles ${ }^{5}$ and Stephanie C. Dulawa'

\begin{abstract}
BTB/POZ domain-containing 3 (BTBD3) was identified as a potential risk gene in the first genome-wide association study of obsessive-compulsive disorder (OCD). BTBD3 is a putative transcription factor implicated in dendritic pruning in developing primary sensory cortices. We assessed whether BTBD3 also regulates neural circuit formation within limbic cortico-striato-thalamo-cortical circuits and behaviors related to OCD in mice. Behavioral phenotypes associated with OCD that are measurable in animals include compulsive-like behaviors and reduced exploration. We tested Btbd3 wild-type, heterozygous, and knockout mice for compulsive-like behaviors including cage-mate barbering, excessive wheel-running, repetitive locomotor patterns, and reduced goal-directed behavior in the probabilistic learning task (PLT), and for exploratory behavior in the open field, digging, and marble-burying tests. Btbd3 heterozygous and knockout mice showed excessive barbering, wheel-running, impaired goal-directed behavior in the PLT, and reduced exploration. Further, chronic treatment with fluoxetine, but not desipramine, reduced barbering in Btbd3 wild-type and heterozygous, but not knockout mice. In contrast, Btbd3 expression did not alter anxiety-like, depression-like, or sensorimotor behaviors. We also quantified dendritic morphology within anterior cingulate cortex, mediodorsal thalamus, and hippocampus, regions of high Btbd3 expression. Surprisingly, Btbd3 knockout mice only showed modest increases in spine density in the anterior cingulate, while dendritic morphology was unaltered elsewhere. Finally, we virally knocked down Btbd3 expression in whole, or just dorsal, hippocampus during neonatal development and assessed behavior during adulthood. Whole, but not dorsal, hippocampal Btbd3 knockdown recapitulated Btbd3 knockout phenotypes. Our findings reveal that hippocampal Btbd3 expression selectively modulates compulsive-like and exploratory behavior.
\end{abstract}

\section{Introduction}

Obsessive-compulsive disorder (OCD) is a psychiatric disorder characterized by intrusive and unwanted thoughts, images, or urges and/or compulsive behaviors ${ }^{1}$. Although OCD is often comorbid with anxiety disorders ${ }^{2}$, the fifth edition of the Diagnostic and Statistical Manual of Mental Disorders (DSM-5) reclassified OCD into a new category of disorders in which compulsive behavior is the

\footnotetext{
Correspondence: Stephanie C. Dulawa (sdulawa@ucsd.edu)

'Department of Psychiatry, University of California San Diego, La Jolla, CA 92093, USA

${ }^{2}$ Committee on Neurobiology, The University of Chicago, Chicago, IL 60637, USA

Full list of author information is available at the end of the article.
}

core feature, consistent with recent hypotheses that compulsivity may comprise a transdiagnostic psychiatric trait $^{3,4}$. Compulsive behaviors are defined as maladaptive repetitive behaviors that are performed despite no longer leading to a goal, and are typically inflexible in nature ${ }^{5-7}$. Unlike obsessions, compulsive behavior can be operationalized in rodent models. For one, chronic treatment with serotonin reuptake inhibitors (SRIs), but not other classes of antidepressants including norepinephrine reuptake inhibitors (NRIs), provide effective treatment for $\mathrm{OCD}^{8}$, and reduce compulsive-like behaviors in rodents including route stereotypy, repetitive jumping, and flipping $^{9-12}$. Furthermore, aspects of compulsive behavior can be measured directly in rodents, such as

\section{(c) The Author(s) 2019}

(c) (i) Open Access This article is licensed under a Creative Commons Attribution 4.0 International License, which permits use, sharing, adaptation, distribution and reproduction in any medium or format, as long as you give appropriate credit to the original author(s) and the source, provide a link to the Creative Commons license, and indicate if changes were made. The images or other third party material in this article are included in the article's Creative Commons license, unless indicated otherwise in a credit line to the material. If material is not included in the article's Creative Commons license and your intended use is not permitted by statutory regulation or exceeds the permitted use, you will need to obtain permission directly from the copyright holder. To view a copy of this license, visit http://creativecommons.org/licenses/by/4.0/. 
neuropsychological endophenotypes in cognitive tasks. Our knowledge of the neurobiological underpinnings of compulsive behavior remain incomplete, and animal models provide an important tool for revealing these mechanisms.

The first genome-wide association study (GWAS) of OCD identified rs6131295, a single nucleotide polymorphism (SNP) located near BTB/POZ domaincontaining 3 (BTBD3), as genome-wide significant in the trio, but not the case-control, portion of the study ${ }^{13}$. This SNP was also an expression quantitative trait locus (eQTL) for $B T B D 3^{13}$, but was not significant in a second GWAS $^{14}$ or a meta-analysis ${ }^{15}$. However, these GWASs were perhaps insufficiently powered to identify genomewide significant loci. The function of BTBD3 has been largely unknown, until a recent report identified a role for BTBD3 in neurodevelopment. BTBD3 was found to orient dendrites toward active axon terminals and regulate activity-dependent dendritic pruning in primary sensory cortex during neonatal development, thus facilitating neural circuit formation ${ }^{16}$. Yet, whether BTBD3 also performs this function in other brain regions in which it is highly expressed, including limbic cortico-striatothalamo-cortical (CSTC) circuits, remains unknown.

In humans and rodents, BTBD3 is highly expressed within limbic CSTC circuitry including the mediodorsal thalamus, anterior cingulate cortex (ACC), and hippocampus $^{17,18}$. Within this circuit, BTBD3 expression increases rapidly during early postnatal development and peaks during childhood and adolescence in humans ${ }^{18}$ and mice ${ }^{16,17}$. Dysfunction within limbic CSTC circuitry is associated with abnormal repetitive behaviors ${ }^{19,20}$, and specifically with compulsive behaviors ${ }^{21,22}$. Furthermore, the hippocampus, mediodorsal thalamus, and ACC are key structures for goal-directed decision-making ${ }^{23-27}$, which is impaired in $\mathrm{OCD}^{28-30}$, and theorized to underlie expression of compulsive behaviors ${ }^{31,32}$. Thus, we aimed to determine the role of BTBD3 in the morphological development of this circuit, and in the expression of compulsive-like behaviors.

Herein, we sought to address three key questions: (i) Does Btbd3 expression modulate behaviors related to OCD, such as compulsive-like behaviors? (ii) Does altering $B t b d 3$ expression affect neuronal morphology within the ACC, mediodorsal thalamus, or hippocampus? (iii) In which region of the limbic CSTC circuit does Btbd3 expression regulate behavioral phenotypes observed? To address these questions, we used $B t b d 3$ wild-type (WT), heterozygous (HT), and knockout (KO) mice to assess behavioral phenotypes and dendritic morphology within the mediodorsal thalamus, ACC, CA1, and dentate gyrus. Finally, we generated and used $B t b d 3^{\text {flox }}$ mice and an adeno-associated virus (AAV) expressing Cre recombinase (Cre) to knockdown (KD) either dorsal or whole hippocampal $B t b d 3$ expression during the early neonatal period, and assessed behavioral consequences during adulthood.

\section{Materials and methods \\ Animals}

Adult (minimum 7 weeks) male and female mice were group-housed by sex on a 12:12 h light:dark cycle ( $500 \mathrm{~lx}$ overhead lighting in housing room) with ad libitum standard chow and water except during cognitive testing (see below). All testing occurred during the light cycle unless otherwise specified. Btbd3 KO mice were on a 129/ B6 background (RIKEN, Saitama, Japan). Experimental cohorts were bred in-house and generated from littermates from heterozygous (HT) Btbd 3 crosses, resulting in variable group sizes based on breeding production. Minimum sample sizes were targeted based on previous experience with these paradigms. Large cohort sizes were used for assessing barbering, based on previous reports of low barbering frequency in control animals ${ }^{33}$. Btbd3floxed $\left(B t b d 3^{\text {flox }}\right)$ mice were generated on a pure C57BL/ 6J background (Transviragen, Research Triangle Park, $\mathrm{NC}$ ) using CRISPR/Cas9 to insert loxP sites flanking exon 2 of $B t b d 3$. Mice weighed 16-35 g. Genotype or viral condition, sex, and home cage were counterbalanced across testing. Sample sizes for each test are listed in the figure legends. All procedures were performed in accordance with the local Institutional Animal Care and Use Committee and the National Institutes of Health Guidelines for the Care and Use of Laboratory Animals.

\section{Drugs}

Drugs were administered in the drinking water in opaque bottles for 14 weeks. The SRI fluoxetine was administered at $80 \mathrm{mg} / \mathrm{L}$ to achieve a $10 \mathrm{mg} / \mathrm{kg} /$ day dose and changed weekly. The NRI desipramine was administered at $215 \mathrm{mg} / \mathrm{L}$ to achieve a $20 \mathrm{mg} / \mathrm{kg} /$ day dose and changed biweekly ${ }^{34,35}$. Fluoxetine and desipramine were used because chronic treatment with SRIs, but not other classes of antidepressants, serve as effective monotherapy for $\mathrm{OCD}^{36,37}$.

\section{Behavioral studies \\ Barbering}

Mice were pair-housed by sex and genotype, photographed weekly, and inspected for evidence of barbering, an abnormal behavior in which animals repetitively clip or pluck the fur of their cage mates, generating bald spots ${ }^{38}$. See Supplementary Information.

\section{Cognitive testing}

Male mice were food-restricted to $85 \%$ of free-feeding bodyweight to motivate responses for food reward, trained to respond on a fixed-ratio 1 (FR1) schedule, and 
then assessed in a Go/No-Go task to measure response inhibition $^{39}$, progressive ratio breakpoint (PRBP) task to measure motivation for reward ${ }^{40}$, and finally the probabilistic learning task (PLT) to measure goal-directed and habitual decision-making strategies ${ }^{41}$. See Supplementary Information.

\section{Wheel-running}

In order to track home-cage locomotor activity, mice were singly housed in standard cages equipped with wireless running wheels (Med Associates, St. Albans, VT). Wheel revolution counts were continuously transmitted to a computer running Wheel Manager Software (Med Associates) for 7 days in the mouse housing room. Mice that never acclimated to running wheels (such as burying the wheel in bedding; quantified as fewer than 300 total wheel revolutions for the entire week) were excluded $(n=6)$.

\section{Open field}

In order to track locomotor activity in a novel environment, mice were placed in a corner of an open field (OF) apparatus (Accuscan, Columbus, $\mathrm{OH}$ ) equipped with a central overhead light $(\sim 100 \mathrm{~lx})$ and activity was monitored for $45 \mathrm{~min}$ in 5-min bins. Versamax software (Accuscan, Columbus, $\mathrm{OH}$ ) generated primary outcome measures including distance traveled (locomotion), vertical rearing (exploration), and center activity (anxiety). The spatial scaling exponent $d$ (spatial $d$ ) was calculated using NightOwl software (Custom) and Python (Python Software Foundation, Beaverton, OR). Spatial $d$ describes the smoothness of the path of the animal, where high values indicate many directional changes, whereas low values indicate a more straight and rigid path, characteristic of compulsive circling in the $\mathrm{OF}^{10,11,42}$.

\section{Dig test}

To measure exploration ${ }^{43}$, mice were placed in novel, clean standard cages with fresh bedding ( $1^{\prime \prime}$ deep) and recorded for $3 \mathrm{~min}^{35}$. Videos were scored by a blind observer for digging behavior, defined by significant displacement of bedding using forelimbs.

\section{Marble-burying}

Marble burying was assessed as an additional measure of exploratory digging ${ }^{44-47}$. Fresh cages were filled with $5 \mathrm{~cm}$ bedding with 12 marbles placed on top in a $3 \times 4$ grid with $4 \mathrm{~cm}$ center-to-center spacing. Number of marbles buried to $2 / 3$ depth was recorded after $30 \mathrm{~min}^{44}$.

\section{Nest-building}

Nest-building is a measure of well-being in mice ${ }^{48}$. Mice were given a pre-weighed compressed cotton nestlet (Ancare, Bellmore, NY) while singly housed in the home cage $^{49}$. In the 8 -h version, nestlets were removed $8 \mathrm{~h}$ later and any unused nestlet was weighed. In the overnight version, nestlets were provided just before initiation of the dark cycle. Fourteen hours later, any unused nestlet was weighed.

\section{Light-dark test}

The light-dark test was performed to assess anxiety-like behavior $^{50}$. The light-dark test was performed in the OF (overhead light adjusted to $\sim 40 \mathrm{~lx}$ ) using dark inserts to cover half the chamber (Omnitech Electronics, Inc., Columbus, OH, USA). Animals began in the dark side of the chamber and activity was recorded for $10 \mathrm{~min}$. Outcome measures were duration on each side, proportion of distance traveled in the dark, and latency to enter the light side.

\section{Novelty-induced hypophagia (NIH)}

$\mathrm{NIH}$ testing assesses anxiety, and was performed as previously described ${ }^{51}$. Briefly, mice underwent three days of training to consume sweetened condensed milk. The following day, mice were presented with sweetened condensed milk in the home cage for $30 \mathrm{~min}$. Latency to drink and consumption volume were measured. The following day, mice were presented with sweetened condensed milk in a novel cage with no bedding and bright lighting for 30 min. Latency to drink and consumption volume were recorded.

\section{Forced swim test (FST)}

Animals were tested in the FST to assess depression-like behavior ${ }^{52}$. Mice were placed in opaque plastic buckets $(18 \mathrm{~cm} \times 20.5 \mathrm{~cm})$ filled with $23-25^{\circ} \mathrm{C}$ water for $6 \mathrm{~min}$. The day prior to testing, animals underwent a $15 \mathrm{~min}$ pretest under the same conditions. Each session was recorded. The video from the test day was hand-scored by a blind observer for time spent immobile, swimming, or climbing in the final $4 \mathrm{~min}$.

\section{Viral-mediated Btbd3 knockdown}

In order to assess the role of hippocampal $B t b d 3$ expression in behavior, postnatal day $2 B t b d 3^{\text {flox }}$ mouse pups received intracranial infusions of AAV expressing Cre: AAV2/8-CMV-Cre-P2A-tdTomato-WPRE (AAVCre; Viral Vector Core Facility, University of Iowa, Iowa City, IA) or control: AAV2/8-CMV-tdTomato-WPRE (AAV-tdTomato), targeting the whole hippocampus $(0.3 \mathrm{~mm}$ anterior, $2.0 \mathrm{~mm}$ lateral, $2.5 \mathrm{~mm}$ ventral of lambda), or only the dorsal half of the hippocampus $(1.0 \mathrm{~mm}$ anterior, $0.3 \mathrm{~mm}$ lateral, $2.7 \mathrm{~mm}$ ventral of lambda). See Supplementary Information. Mice were assessed for behavior during adulthood (8-13 weeks) in a subset of paradigms tested in the global $B t b d 3 \mathrm{KO}$ mice. 


\section{Statistical analysis}

Dependent measures were analyzed using repeated measures or factorial analysis of variance (ANOVA). Significant interactions were resolved by assessing simple main effects for factors with more than two groups with Bonferroni correction. Post hoc tests for between-subjects factors were performed using Student-Newman-Keuls. Where appropriate, Kruskal-Wallis one-way ANOVAs were performed, and Mann-Whitney $U$ tests with Bonferroni correction were used as post hoc tests. Categorical dependent measures were analyzed using chi-square tests for endpoint factors which were confirmed with a bootstrap analysis, and Kaplan-Meier survival curves with Mantel-Cox logrank tests for repeated measures analyses. Alpha was set at 0.05 . A few mice were excluded from analyses because of experimental errors, but no statistical outliers were removed.

\section{Results}

\section{Btbd3 KO mice exhibit compulsive-like behavior}

We observed a high frequency of cage-mate barbering in Btbd3 $\mathrm{KO}$ colony home cages (Fig. 1a); therefore, we monitored barbering behavior by pair-housing mice of identical sex and genotype. Chi-square analysis revealed that barbering was unevenly distributed across the three genotypes (Fig. 1b; $X^{2}{ }_{(2, n=647)}=11.38 ; p<$ 0.005). Btbd3 HT $\left(X_{(1, n=486)}^{2}=7.73 ; p<0.01\right)$ and $\mathrm{KO}$ $\left(X_{(1, n=332)}^{2}=11.77 ; p<0.0001\right)$ groups each had an increased incidence of barbering compared to WT. A bootstrap analysis $(100,000$ iterations) confirmed that all of the chi-square statistics above were unlikely ( $p$ 's $<0.05)$ to be due to the uneven group numbers that resulted from heterozygous breeding in this observational cohort. Bald patches in the fur were observed primarily on the dorsal surface of the body and the face, characteristic of barbering by cage mates, rather than self-barbering ${ }^{33}$.

We then assessed the effects of OCD-effective (SRI fluoxetine) or OCD-ineffective antidepressant treatment (NRI desipramine) on barbering ${ }^{36,37}$ for 14 weeks to determine whether barbering may be a compulsive-like phenotype. Pooled across genotypes, log-rank tests revealed that fluoxetine reduced the onset of barbering relative to vehicle starting at 4 weeks of treatment (Fig. 1c), and throughout the remainder of treatment, except for weeks 7 and 8 (Supplementary Information). In contrast, desipramine did not affect onset of barbering $\left.\left(X_{(1,}^{2} \quad n=177\right)=2.09 ; \quad p=0.15\right)$. Furthermore, within fluoxetine-treated animals, a genotype effect was identified $\left(X_{(2, n=95)}^{2}=16.75 ; p<0.0005\right)$. Therefore, the effect of fluoxetine on barbering within each genotype was examined. Within Btbd3 WT mice, fluoxetine prevented barbering onset (Fig. 1d), and this effect was significant by 6 weeks of treatment $\left(X_{(1, n=56)}^{2}=4.59\right.$; $p<0.05)$. Within Btbd3 HT mice, fluoxetine became effective at 12 weeks of treatment (Fig. 1e; $X_{(1, n=64)}^{2}=$ 4.50; $p<0.05)$ and remained significant through week 14 $\left(X^{2}{ }_{(1, n=64)}=4.50 ; p<0.05\right)$. In contrast, fluoxetine never affected Btbd3 KO barbering incidence (Fig. 1f; week 14: $\left.X_{(1, n=65)}^{2}=0.40 ; p=0.53\right)$. These effects were not due to genotypic differences in fluoxetine metabolism (Supplementary Information).

Next, we tested cognitive domains relevant to compulsive disorders using operant conditioning. ANOVAs revealed that there was no effect of genotype on FR1 training $\left(F_{(2,49)}=0.27 ; p=0.76\right)$ or on false alarm rate in the Go/No-Go task (Supplementary Information), which measures response inhibition ${ }^{39,53}$. In the PLT, which measures reinforcement learning and response strategies $^{41}$, no effects of genotype were identified for Block 1 (reward probabilities of $90 \% / 10 \%$ ) or Block 2 (reward probabilities of $80 \% / 20 \%$; data not shown). However, in Block 3 (reward probabilities of 70\%/30\%), Btbd3 KO mice were less accurate than WT or HT mice (Fig. 1g; $\left.F_{(2,35)}=8.01 ; p<0.005\right)$. An ANOVA and post hoc tests revealed a higher proportion of target lose-shift responses in Btbd3 KO mice versus WT mice $\left(F_{(2,35)}=4.96 ; p<\right.$ 0.05; Fig. 1h). Furthermore, Btbd3 KO mice more frequently reselected the non-target port after being rewarded than WT mice (Fig. 1i; $F_{(2,23)}=4.24 ; p<0.05$ ). Genotype did not affect target win-stay or non-target lose-shift patterns (Supplementary Fig. 1d, e). Lastly, mice were assessed in the PRBP test for any potentially confounding effects of genotype on motivation in the PLT, but genotype did not affect breakpoint (Fig. 1j; $F_{(2,43)}=$ $1.58 ; p=0.22$ ).

Next, wheel-running was assessed, which is excessive in some rodent models of compulsive behavior ${ }^{54}$. A threeway interaction of day, cycle, and genotype was identified by a repeated measures ANOVA for wheel revolutions $\left(F_{(12,312)}=2.32 ; p<0.01\right)$. Post hoc ANOVAs and then post hoc tests revealed that Btbd3 $\mathrm{KO}$ mice accrued more wheel revolutions than WT or HT mice during the dark cycle (Fig. $1 \mathrm{k} ; F_{(2,55)}=4.57 ; p<0.05$ ), but not the light cycle $\left(F_{(2,55)}=0.35 ; p=0.70\right.$; data not shown).

\section{Btbd3 KO mice show reduced exploration}

We next assessed exploration in Btbd3 mice, as noveltyseeking is reduced in $\mathrm{OCD}^{55-58}$. In the OF test, a genotype by bin interaction $\left(F_{(16,1040)}=2.57 ; p<0.0001\right)$ in a repeated measures ANOVA and post hoc tests revealed that $B t b d 3 \mathrm{KO}$ mice traveled a greater total distance than WT or HT mice in bins 1-4 (Fig. 2a). All genotypes exhibited locomotor habituation (Supplementary Information). $B t b d 3 \mathrm{HT}$ and $\mathrm{KO}$ mice had reduced instances of vertical rearing relative to WT mice (Fig. $2 \mathrm{~b} ; F_{(2,130)}=6.97 ; p<$ 0.005 ) and spent less time rearing than WT mice (Fig. 2c; $\left.F_{(2,130)}=7.18 ; p<0.005\right)$. 


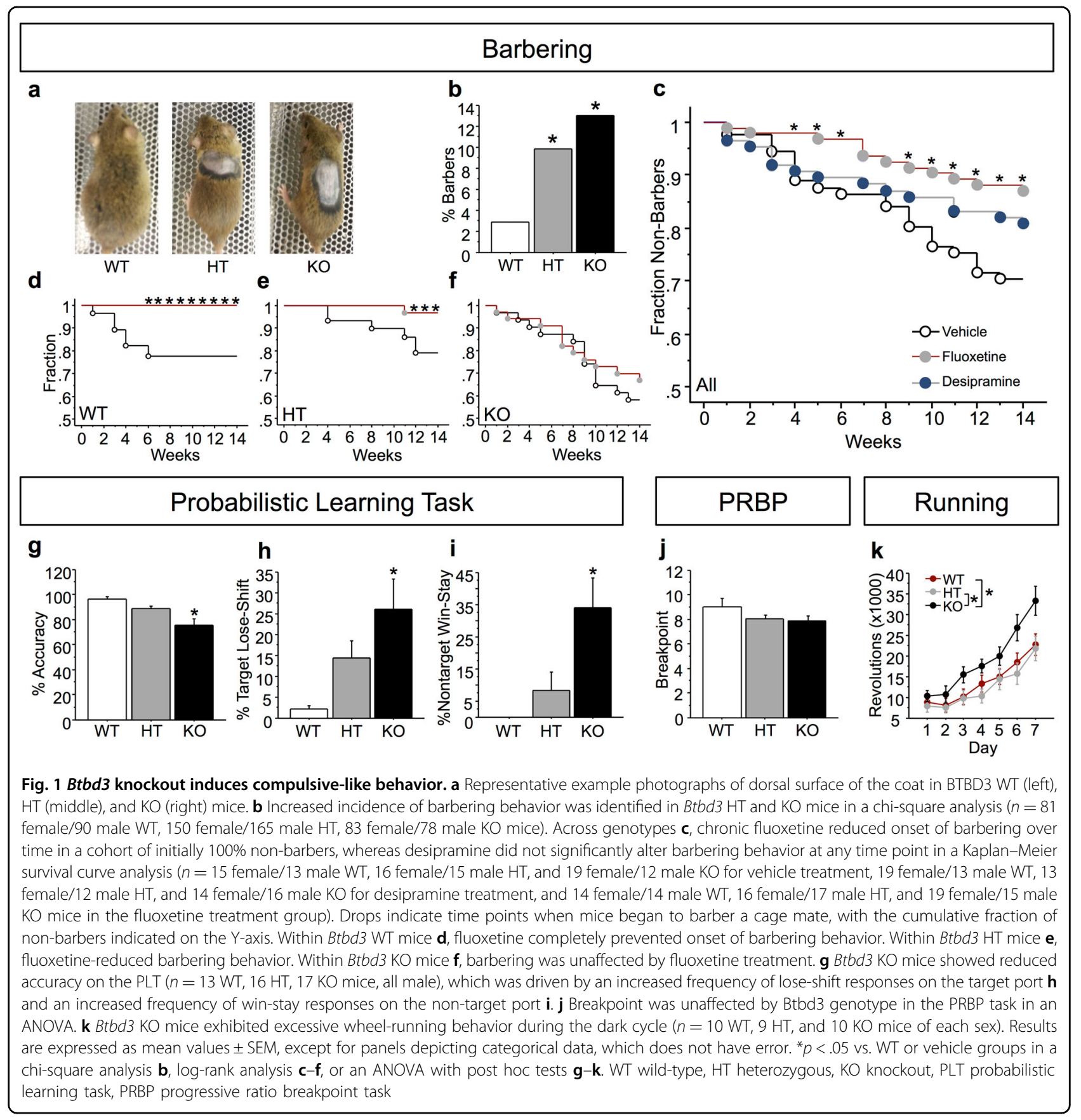

$B t b d 3$ mice were then assessed for exploratory digging. The distribution of the data violated the normality assumption for using parametric tests even after attempts at transforming the data, so nonparametric statistics were used. A Kruskal-Wallis one-way ANOVA found a main effect of genotype on latency to $\operatorname{dig}\left(H_{(2)}=6.43 ; p<0.05\right)$, with $B t b d 3 \mathrm{KO}$ mice showing a longer latency to dig than WT mice (Fig. 2d; $U=289 ; p<0.025$ ). Furthermore, Btbd3 KO mice spent less time digging than WTs (Fig. 2e; $\left.H_{(2)}=5.93 ; p<0.05 ; U=286 ; p<0.025\right)$. Lastly, genotype altered bout duration $\left(H_{(2)}=8.20 ; p<0.05\right)$, with $B t b d 3$ KO mice performing briefer digging bouts than WT mice (Fig. 2f; $U=265 ; p<0.025$ ). No effect of genotype was identified for number of digging bouts (Fig. 2g; $H_{(2)}=$ 4.36; $p=0.11$ ).

$B t b d 3$ mice were tested in the marble-burying paradigm to confirm genotype effects on digging behavior ${ }^{44-47}$. An ANOVA and post hoc tests revealed that Btbd3 $\mathrm{KO}$ mice buried fewer marbles than WT or HT mice (Fig. 2h; $\left.F_{(2,66)}=5.56 ; p<0.01\right)$. 


\section{Open Field}

a

b
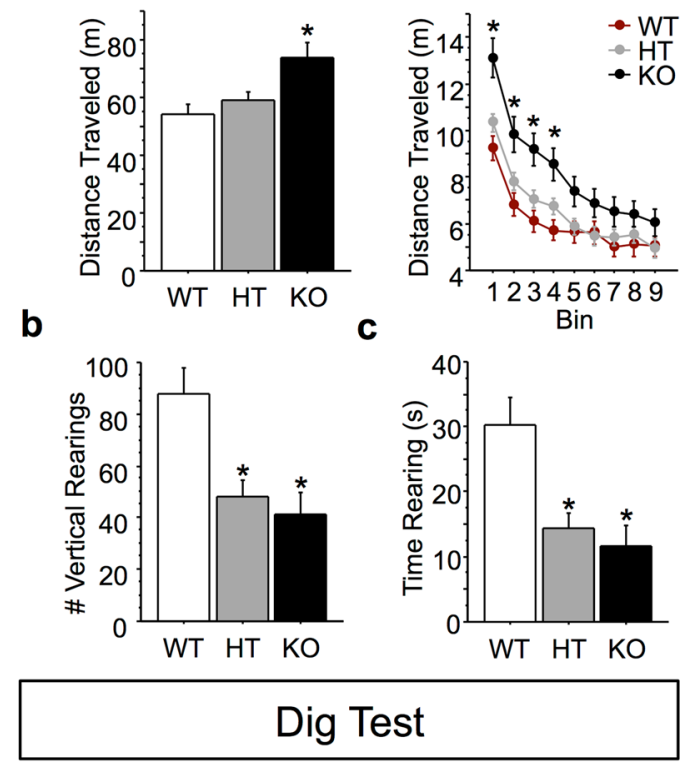

d

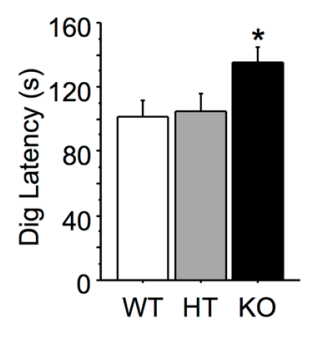

$\mathbf{f}$
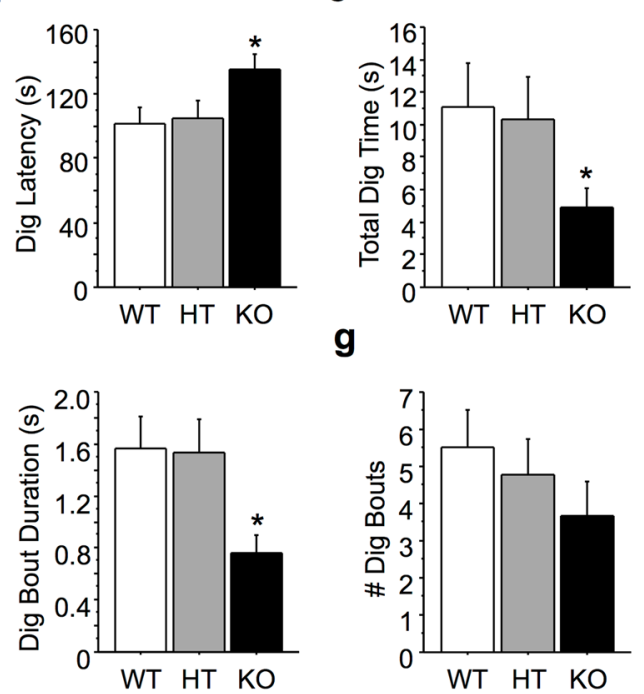

Marble-Burying \& Nest-Building

h

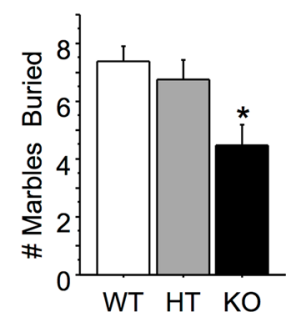

i

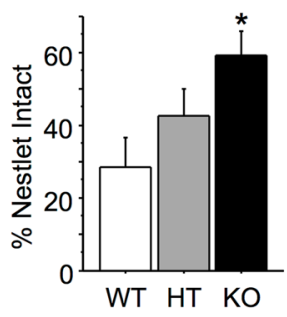

Fig. 2 Btbd3 knockout reduces exploration. a Btbd3 KO mice traveled a greater total distance in the OF $(n=17$ female/27 male WT, 34 female/27 male HT, and 11 female/20 male KO mice) than HT or WT mice overall (left panel), which was confined to the first 20 min of testing as revealed by the 5 -min bin analysis (right panel). b Btbd3 HT and $\mathrm{KO}$ mice showed fewer instances of vertical rearing and $\mathbf{c}$ spent less time rearing across the session than WT mice in the OF. $\mathbf{d}-\mathbf{g}$ In the dig test ( $n=13$ female/14 male WT, 15 female/16 male HT, 20 female/13 male KO mice), Btbd3 KO mice had a greater latency to initiate digging behavior $\mathbf{d}$, reduced total time spent digging $\mathbf{e}$, and dug in briefer bouts than controls $\mathbf{f}$. The number of dig bouts in the dig test was unaffected by Btbd3 genotype $\mathbf{g}$. $\mathbf{h}$ Btbd3 KO mice buried fewer marbles ( $n=14$ female/12 male WT, 12 female/12 male HT, 9 female/13 male KO mice) than WT mice in the marble-burying test. $\mathbf{i}$ Btbd3 KO mice left a greater portion of the nestlet intact than WT mice in the 8-h nest-building paradigm ( $n=12 /$ genotype/sex). Results are expressed as mean values \pm SEM. ${ }^{*} p<0.05$ vs. WT group in ANOVAs resolved with post hoc tests. WT wild-type, HT heterozygous, KO knockout, OF open field

Nest-building is considered a measure of well-being in mice $^{48}$, and nest-building deficits have been found in numerous neuropsychiatric disorder models ${ }^{59-62}$. In the nest-building task, a main effect of genotype was identified for original nestlet percentage remaining intact in an ANOVA $\left(F_{(2,65)}=4.33 ; p<0.05\right)$, with post hoc tests showing that Btbd3 $\mathrm{KO}$ mice left more nestlet untouched than WT mice (Fig. 2i).

Btbd3 does not modulate anxiety-like or depression-like behaviors or basic sensory and motor functioning

Anxiety and depression are often comorbid with $\mathrm{OCD}^{2,63}$. Thus, Btbd3 mice were assessed for anxiety-like and depression-like behaviors. In the light-dark test, no effects of genotype were identified for either duration on the light versus the dark side of the chamber (Fig. 3a) or percent distance traveled in the dark side (Fig. 3b). An ANOVA revealed a main effect of side of the chamber for duration $\left(F_{(1,84)}=140.97 ; p<0.0001\right)$, indicating that animals spent more time on the dark side. In the OF test, no effect of genotype was identified for proportion of distance traveled in the center (Fig. 3c) or time spent in the center (Fig. 3d). Mice were assessed in the NIH test as an additional measure of anxiety-like behavior. Since latency data are often skewed, we examined the distribution of the data, and as a result log-transformed latency to drink for statistical analysis. Neither a main effect of genotype nor an interaction between genotype and cage condition was identified for latency to drink (Fig. 3e). A main effect of cage condition on latency to drink was identified $\left(F_{(1,49)}=152.30 ; p<0.0001\right)$, indicating a longer latency to consume the sweetened condensed milk in the novel cage. No effects of genotype were found for total consumption (Fig. 3f). A main effect of cage 

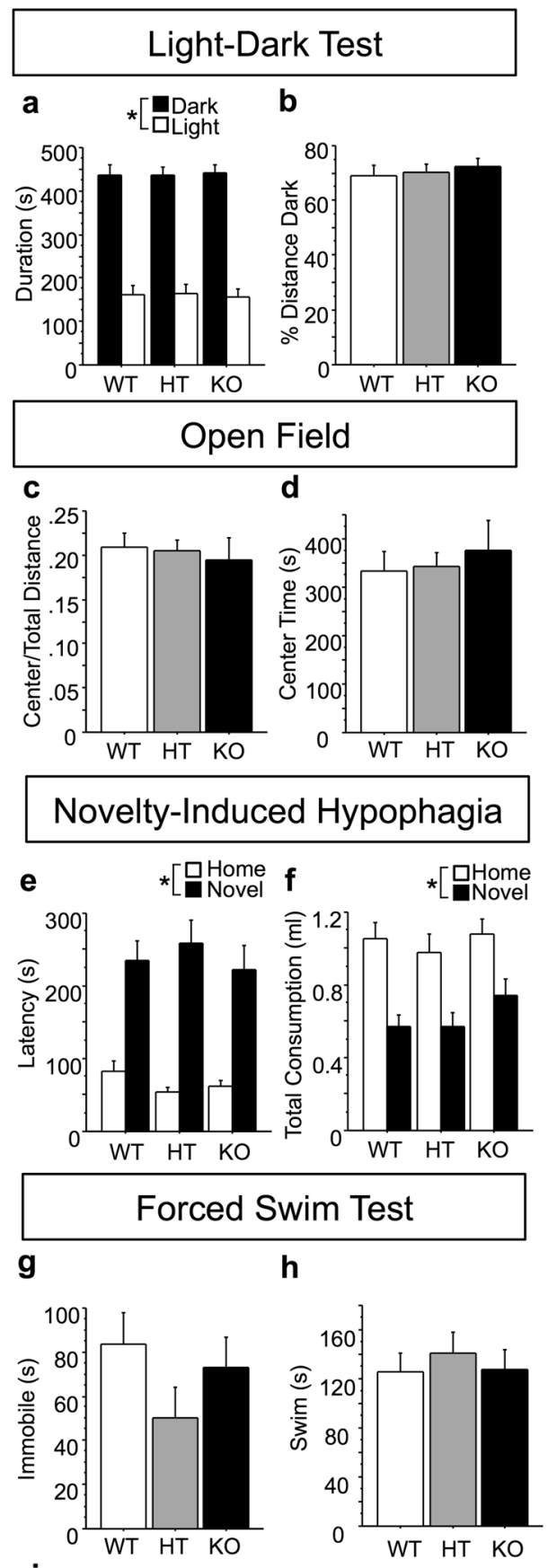

i

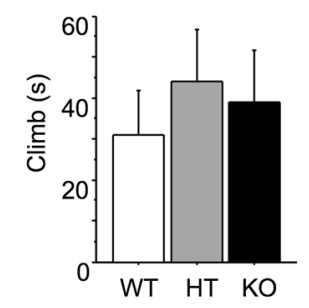

Fig. 3 BTBD3 does not affect anxiety-like or depression-like behavior. Btbd3 genotype had no effect on proportion of time spent $\mathbf{a}$ or distance traveled $\mathbf{b}$ in the dark side of the light-dark box ( $n=15$ / genotype/sex), proportion of distance traveled $\mathbf{c}$ or time spent in the center $\mathbf{d}$ of the OF ( $n=17$ female/27 male WT, 34 female/27 male HT, and 11 female/20 male KO mice), total latency to drink $\mathbf{e}$, or total consumption $\mathbf{f}$ of sweetened condensed milk in the $\mathrm{NIH}(n=10$ each female/male WT, 10 female/ 9 male HT, 9 each female/male KO mice), time spent immobile $\mathbf{g}$, swimming $\mathbf{h}$, or climbing $\mathbf{i}$ in the FST ( $n=10$ / genotype/sex, except female WT $n=9$ ). Results are expressed as mean values \pm SEM. ${ }^{*} p<0.05$ between conditions (dark versus light; home versus novel cage) as determined by ANOVAs. OF open field, $\mathrm{NIH}$ novelty-induced hypophagia, FST forced swim test

condition was identified for total consumption $\left(F_{(1,51)}=\right.$ 102.50; $p<0.0001)$, indicating reduced consumption of sweetened condensed milk in the novel versus the home cage.

Btbd3 mice were assessed in the FST to evaluate depression-like behavior. No effect of genotype was identified for time spent immobile (Fig. 3g), swimming (Fig. 3h), or climbing (Fig. 3i).

Finally, basic sensorimotor functioning was assessed in $B t b d 3$ mice to screen for potentially confounding effects on compulsive-like and exploratory behaviors. No effects of genotype were found in auditory, olfactory, somatosensory, or motor function (Supplementary Fig. 1f, g; 2). See Supplementary Information.

\section{Effects of Btbd3 expression on limbic CSTC dendritic morphology}

Dendritic morphology was assessed in limbic CSTC brain regions with dense $B t b d 3$ expression because BTBD3 was previously reported to play a role in dendritic morphology ${ }^{16}$. No effects of genotype were identified for dendritic branching or spine density in the CA1 or dentate gyrus subregions of hippocampus, or in the mediodorsal thalamus. However, increased spine density in $B t b d 3 \mathrm{KO}$ mice was identified in the ACC (Supplementary Fig. 3). See Supplementary Information.

\section{Whole hippocampal Btbd3 KD induces compulsive-like behavior and decreases exploration}

Due to robust $B t b d 3$ expression in hippocampus ${ }^{17}$ and the role of hippocampus in several behavioral phenotypes for which deficits were identified in $B t b d 3 \mathrm{KO}$ mice ${ }^{45,64}$, we assessed the effects of neonatal, whole hippocampal $B t b d 3$ $\mathrm{KD}$ on behavior during adulthood. We confirmed KD of Btbd3 RNA (Fig. 4a, top left panel; $F_{(1,7)}=46.39 ; p<$ 0.0005 ) and protein (Fig. 4a, top right panel; $F_{(1,4)}=22.10$; $p<0.01)$ in the hippocampus of $B t b d 3^{\text {flox }}$ mice receiving viral infusion of AAV-Cre versus AAV-tdTomato. Btbd3 


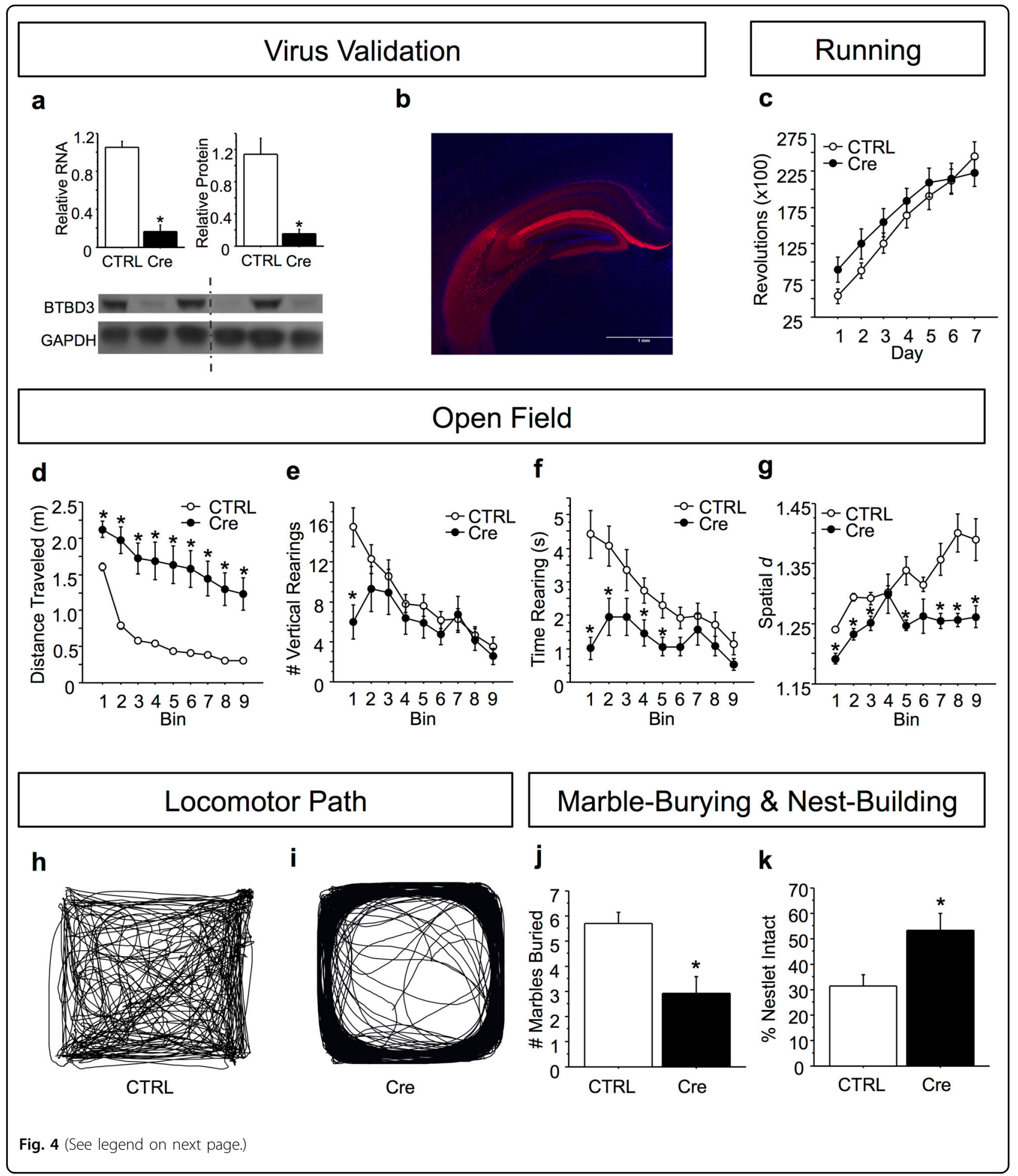

KD did not alter wheel-running (Fig. 4c), but increased locomotor activity (Fig. 4 d; $F_{(1,70)}=48.85 ; p<0.0001$ ) and reduced locomotor habituation in the OF (Supplementary Information). Btbd3 KD mice had reduced instances of rearing within the first $5 \mathrm{~min}$ (Fig. $4 \mathrm{e} ; F_{(8,560)}=3.93 ; p<$
0.0005). For time spent rearing (Fig. 4f), an interaction between viral condition and bin $\left(F_{(8,560)}=3.49 ; p<0.001\right)$ and post hoc tests revealed that Btbd3 KD mice spent less time rearing than control mice in time bins $1,2,4$, and 5 . Btbd3 KD mice exhibited reductions in spatial $d$ within 


\begin{abstract}
(see figure on previous page)
Fig. 4 Neonatal Btbd3 knockdown in whole hippocampus recapitulates the Btbd3 knockout phenotype. Cre virus successfully knocked down RNA (a, top left) and protein (a, top right; bottom) in hippocampus in a qPCR assay ( $n=7$ AAV-tdTomato, 2 AAV-Cre virus) and a western blot ( $n=3$ / virus) relative to CTRL, respectively. The western blot image (a, bottom) shows samples from CTRL virus-infused mice in lanes 1 , 3, and 5, and samples from Btbd3 KD mice in lanes 2, 4, and 6. The dotted line indicates that the image was interrupted between these lanes in order to remove space between the lanes, but the left and right-hand sides are from the same image of the blot. $\mathbf{b}$ Representative example of viral reporter tdTomato expression in hippocampus. c Hippocampal Btbd3 KD did not affect number of wheel revolutions in the voluntary home cage wheel-running assessment ( $n=19$ female/25 male AAV-tdTomato and 15 female/12 male AAV-Cre infused mice). d Hippocampal Btbd3 KD increased distance traveled in the OF throughout testing ( $n=19$ female/26 male AAV-tdTomato and 16 female/13 male AAV-Cre infused mice). e Hippocampal Btbd3 $\mathrm{KD}$ reduced instances of vertical rearing only within the first 5-min bin. $\mathbf{f}$ Hippocampal Btbd3 $\mathrm{KD}$ reduced time spent rearing in the first half of testing. g Hippocampal Btbd3 KD reduced spatial $d$ throughout testing (example traces in $\mathbf{h}$, i). Hippocampal Btbd3 KD mice buried fewer marbles in the marble-burying paradigm ( $n=19$ female/26 male AAV-tdTomato and 16 female/13 male AAV-Cre infused mice) $\mathbf{j}$ and left more nestlet unused in the overnight nest-building test $\mathbf{k}$ than CTRL mice ( $n=19$ female/26 male AAV-tdTomato and 16 female/13 male AAV-Cre infused mice). Results are expressed as mean values \pm SEM. ${ }^{*} p<0.05$ vs. CTRL group in ANOVAs resolved with post hoc tests. KD knockdown, CTRL control virus: AAV-tdTomato, OF open field, AAV adeno-associated virus, qPCR quantitative polymerase chain reaction, Cre AAV-Cre virus
\end{abstract}

each time bin (Fig. 4g), except bins 4 and 6 (Fig. 4h, i; $\left.F_{(8,504)}=2.32 ; p<0.05\right)$.

Btbd3 KD mice buried fewer marbles than control mice in the marble-burying test (Fig. 4 j; $F_{(1,70)}=10.87 ; p<$ $0.005)$ and used less nestlet than control mice in the nestbuilding test $\left(F_{(1,70)}=6.47 ; p<0.05\right)$ as determined by an ANOVA followed by post hoc tests (Fig. 4k).

\section{Dorsal hippocampal Btbd3 KD does not mimic the Btbd3 KO phenotype}

Next, we investigated whether Btbd3 KD in dorsal hippocampus, which was recently implicated in goaldirected planning ${ }^{26}$, would be sufficient to induce the $B t b d 3$ behavioral profile. No effect of $B t b d 3 \mathrm{KD}$ was identified on wheel-running (Fig. 5b), distance traveled (Fig. 5c), instances or time spent rearing (Fig. 5d, e), spatial $d$ (Fig. 5f), or marble-burying (Fig. 5g; $F_{(1,25)}=1.85$; $p=0.19$ ) in ANOVAs. The only effect of neonatal Btbd3 $\mathrm{KD}$ in dorsal hippocampus was impaired nest-building in the nest-building test (Fig. 5h; $F_{(1,25)}=4.58 ; p<0.05$ ).

\section{Discussion}

Our results show that BTBD3 regulates compulsive-like and exploratory behaviors across multiple paradigms in mice. Btbd3 HT and KO mice exhibited increased barbering, which was reduced by effective (SRI), but not ineffective (NRI), OCD treatment. Additionally, Btbd3 KO mice exhibited excessive wheel-running and poor goaldirected decision-making, a trait that is thought to underlie compulsive behavior. Btbd3 $\mathrm{HT}$ and $\mathrm{KO}$ mice were less exploratory in the $\mathrm{OF}$, dig, and marble-burying tests. Furthermore, whole hippocampal, but not dorsal, neonatal $B t b d 3 \mathrm{KD}$ increased compulsive-like behaviors and reduced exploration during adulthood, largely mimicking the phenotype of constitutive Btbd3 $\mathrm{KO}$ mice. Surprisingly, Btbd3 knockout spared dendritic morphology within hippocampal subregions, but increased spine density in ACC layer II/III pyramidal neurons, suggesting that an alternative function of Btbd3 may mediate the hippocampus-dependent behavioral effects observed. Our findings indicate that reduced hippocampal Btbd3 expression leads to the development of compulsive-like behaviors and reductions in exploration.

Btbd3 HT and KO mice exhibited compulsive-like behaviors indicated by increased barbering, wheel-running, and impaired goal-directed behavior. Barbering is an abnormal behavior observed only in confined animals ${ }^{38}$, and is considered a repetitive, compulsive-like behavior $^{33,54,65}$. The idea that barbering is a compulsive-like behavior is reinforced by our finding that chronic SRI, but not NRI, treatment reduced barbering, paralleling treatment response in $\mathrm{OCD}^{8}$. Interestingly, our finding that barbering incidence was reduced by chronic fluoxetine treatment in Btbd3 WT and HT, but not KO mice suggests that Btbd3 expression may be required for these anti-compulsive effects of fluoxetine. Increased barbering has previously been reported in other genetically altered mouse lines exhibiting a compulsive-like phenotype ${ }^{66}$, and has been associated with deficits in extradimensional shifting ${ }^{65}$, which measures cognitive flexibility ${ }^{7}$ and is deficient in $\mathrm{OCD}^{67-69}$. While excessive wheel-running has also been proposed as compulsive-like in rodent food restriction-induced hyperactivity models based on the pharmacological response profile ${ }^{70,71}$, effects across studies are not fully consistent with $\mathrm{OCD}^{72}$. Thus, the relationship between excessive wheel-running and compulsivity appears somewhat unclear ${ }^{73}$. Alternatively, other mouse lines exhibiting a compulsive-like phenotype have also reported increased barbering and excessive wheel-running ${ }^{54}$, suggesting that these phenotypes may be linked. In addition to increased barbering and wheelrunning, Btbd3 $\mathrm{KO}$ mice also exhibited impaired decision-making in the PLT, which assesses the balance of goal-directed versus habitual decision-making strategies during reinforcement learning ${ }^{41,74}$. Compulsive behavior has been associated with alterations in this balance, with a 


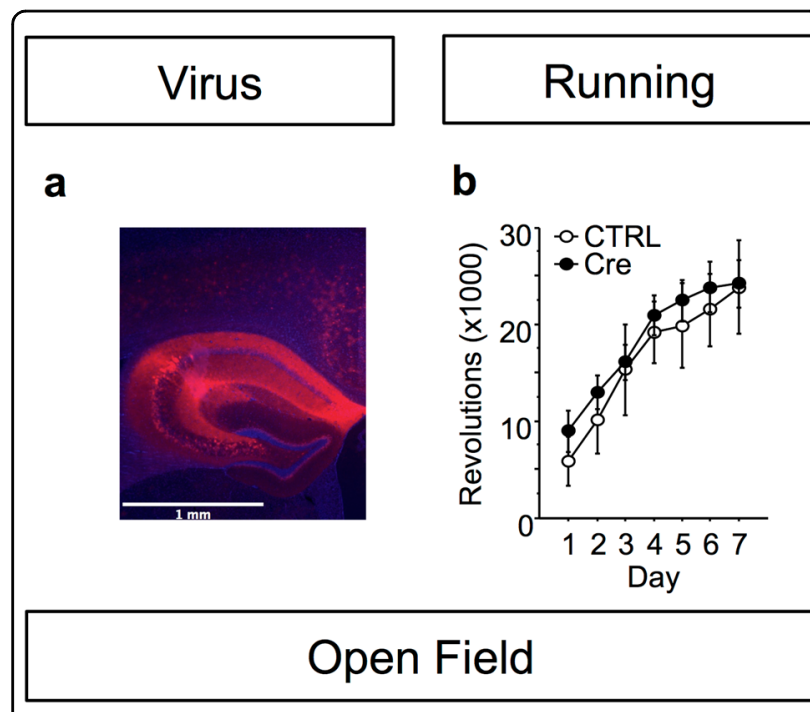

\section{C}

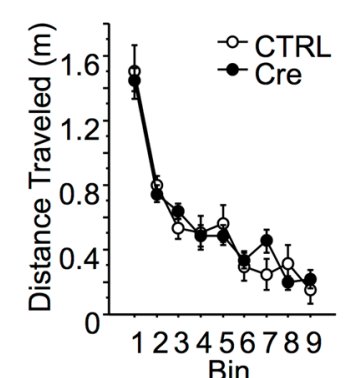

e

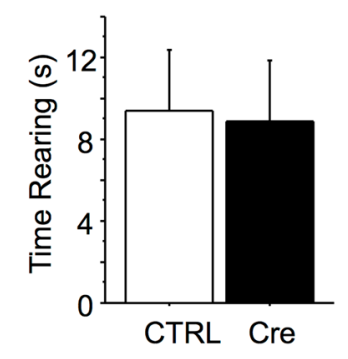

d

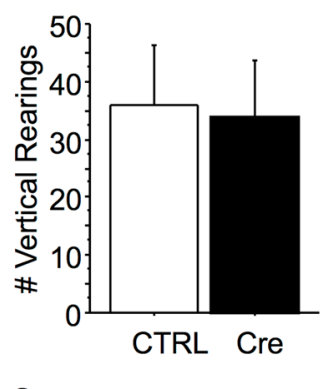

$\mathbf{f}$

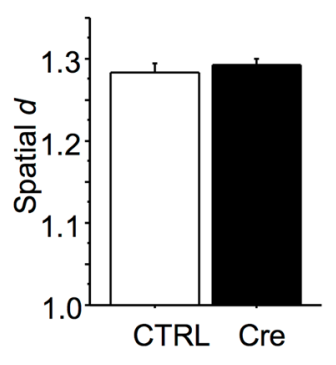

\section{Marble-Burying \& Nest-Building}

g

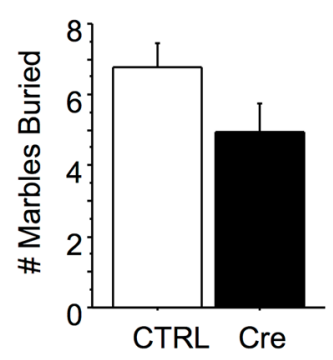

h

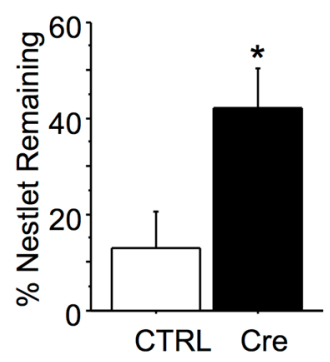

Fig. 5 Neonatal Btbd3 knockdown in dorsal hippocampus does not recapitulate the $B t b d 3$ knockout phenotype. a Example of viral reporter tdTomato expression in dorsal hippocampus. b Dorsal hippocampal Btbd3 KD did not affect number of revolutions in wheelrunning ( $n=5$ female/4 male AAV-tdTomato, 9 female/9 male AAVCre mice), $\mathbf{c}$ distance traveled in the OF $(n=5$ female/ 4 male AAVtdTomato, 11 female/9 male AAV-Cre mice), vertical rearing in the OF d, e, spatial $d$ in the OF $\mathbf{f}$, or $\mathbf{g}$ marble-burying $(n=5$ female/4 male AAV-tdTomato, 11 female/9 male AAV-Cre mice). $\mathbf{h}$ Neonatal dorsal hippocampal Btbd3 KD mice left more nestlet unused than CTRL mice in the nest-building paradigm ( $n=5$ female/4 male AAV-tdTomato, 11 female/9 male AAV-Cre mice). Results are expressed as mean values \pm SEM. ${ }^{*} p<0.05$ vs. CTRL group in ANOVAs resolved with post hoc tests. KD knockdown, CTRL control virus: AAV-tdTomato

shift toward more habitual, and less goal-directed tendencies $^{3,4}$, as observed in OCD patients ${ }^{28-30}$. Thus, goaldirected learning impairments are thought to contribute to the development of compulsivity ${ }^{31,32}$. Therefore, the reduction in goal-directed decision-making we observed in Btbd3 $\mathrm{KO}$ mice is consistent with the increases in barbering and wheel-running we also observed in these mice. That Btbd3 KO mice exhibit multiple different compulsive-like phenotypes is consistent with evidence that discrete types of repetitive behaviors are interrelated and subserved by partially overlapping CSTC circuitry ${ }^{19}$.

Btbd3 HT and KO mice also exhibited reduced exploratory drive. Robust reductions in vertical rearing were found in Btbd3 $\mathrm{HT}$ and $\mathrm{KO}$ mice. Btbd3 $\mathrm{KO}$ mice also showed reduced digging ${ }^{43}$ and marble-burying. While increased marble-burying has been widely used as a measure of anxiety-like or compulsive-like behavior, this behavior is reduced by many compounds that are ineffective treatments for anxiety or compulsivity ${ }^{73,75}$, including acute treatment with $\mathrm{SRIs}^{76}$. Furthermore, several rodent models of abnormal repetitive behavior exhibit reductions in marble-burying, concomitant with reduced digging or vertical rearing behavior ${ }^{77-79}$. Thus, marble-burying has also been suggested to measure exploration $^{44-46}$. Interestingly, exploration is an integral component of goal-directed behavior ${ }^{80}$, suggesting that these two impairments in Btbd3 $\mathrm{KO}$ mice might be related. Moreover, novelty-seeking, a trait that drives exploration, is reduced in patients with $\mathrm{OCD}^{55-58}$. Lastly, Btbd3 KO mice also showed impaired nest-building, which has been associated with reduced well-being ${ }^{48}$.

Interestingly, anxiety-like and depression-like behaviors were unaltered in Btbd3 $\mathrm{HT}$ and $\mathrm{KO}$ mice. Anxiety-like behavior was unaffected in the light-dark, OF, and $\mathrm{NIH}$ tests, well-established anxiety measures in rodents. These results strongly suggest that reduced exploration in Btbd3 $\mathrm{HT}$ and KO mice does not reflect augmented anxiety, consistent with previous reports that exploration and 
anxiety-like behavior are dissociable ${ }^{81}$. Furthermore, depression-like behavior was unaffected by genotype in the FST. Thus, our findings suggest that the behavioral phenotypes observed in Btbd3 $\mathrm{KO}$ mice are not modulated by anxiety-like or depression-like states. While anxiety and depression are highly comorbid with $O C D^{2,63}$, anxiety and affective disorders are distinct from OCD. For example, traits characteristic of OCD, eating disorders, and addiction correlate with goal-directed behavior deficits in humans, whereas anxiety and depression do not ${ }^{3}$, suggesting distinct neuropsychological endophenotypes between these classes of disorders. Moreover, SRIs and NRIs serve as effective treatment for anxiety and depres$\operatorname{sion}^{82-85}$, whereas only SRIs provide effective monotherapy in $\mathrm{OCD}^{8}$, a treatment profile that parallels our barbering results. This distinction is further reflected in the DSM-5, which removed OCD from the anxiety disorders category and does not include anxiety as a core symptom of $\mathrm{OCD}^{1}$. Thus, our results suggest that BTBD3 may modulate neural processes contributing to compulsive-like behaviors, including impaired exploratory drive and/or reduced goal-directed behavior, which are independent of anxious-depressive phenotypes. The Btbd3 behavioral profile is thus distinct from several genetic mouse models of OCD, which exhibit a repetitive behavior, such as excessive self-grooming or self-barbering concomitant with increased anxiety-like behaviors ${ }^{66,86,87}$.

We did not observe effects of Btbd3 genotype on additional behavioral measures including motivation, startle, or sensorimotor behaviors. Motivation was unaltered in Btbd3 $\mathrm{HT}$ and KO mice in the PRBP, as was response inhibition as indicated by false alarm rate in the Go/No-Go task (Supplementary Fig. 1b). Btbd3 HT and $\mathrm{KO}$ mice also did not show differences in sensorimotor gating (Supplementary Fig. 1f) or startle reactivity (Supplementary Fig. 1g). Furthermore, no effects of Btbd3 genotype were observed on sensory or motor measures in the olfactory dis/habituation or olfactory memory tests, the whisker-brushing test, or the footprint test (Supplementary Fig. 2a-i). Young adult Btbd3 KO mice had modestly reduced bodyweight, which was unlikely to confound the other tests performed (Supplementary Fig. 2j): although, we note the common genetic variation overlap between OCD and anorexia nervosa, and the negative genetic correlation of both with body mass index ${ }^{88}$. Lastly, no effects of sex were found for the phenotypic differences identified.

Neonatal Btbd3 KD in the whole hippocampus induced compulsive-like behavior and reduced exploration during adulthood, mirroring the phenotype observed in constitutive Btbd3 KO mice, with minor exceptions. Although both models showed exploration deficits, increased locomotion in the OF, and increased compulsive-like behavior, hippocampal Btbd3 KD mice showed decreased spatial $d$ but unaltered wheel-running, while constitutive Btbd3 $\mathrm{KO}$ mice showed the opposite pattern. These discrepancies may reflect different compensatory changes or distinct $B t b d 3$ expression patterns. We did not assess barbering in the Btbd3 KD cohorts due to the large sample sizes required for these observations. Interestingly, a pharmacological mouse model of aspects of OCD shows a highly similar behavioral profile, in which 5-HT1B receptor stimulation induces hyperactivity, low spatial $d$, reduced vertical rearing, reduced exploratory digging, and impaired delayed alternation performance $e^{10,11,35,89}$. This observation further suggests that reduced species-typical exploratory behaviors may be causally related to increased compulsive-like behaviors. Importantly, neonatal Btbd3 KD in the dorsal half of the hippocampus did not produce any of the behavioral effects of whole hippocampal Btbd3 KD, except for nestbuilding deficits. Altogether, our findings suggest that Btbd3 KD in the whole, but not dorsal, hippocampus induces compulsive-like behavior and reductions in exploration.

Surprisingly, Btbd3 genotype altered dendritic morphology in ACC layer II/III pyramidal neurons, but not in the mediodorsal thalamus, or CA1 or dentate gyrus of the hippocampus (Supplementary Fig. 3). This result was unexpected given the important role of BTBD3 in dendritic morphology in the developing barrel cortex ${ }^{16}$, and suggests that additional region-specific functions of BTBD3, or compensatory changes in constitutive Btbd3 KO mice produced the observed phenotypes. For instance, BTBD3 interacts with cell signaling proteins, such as SEC24C, which is required for trafficking the serotonin transporter to the cell membrane $e^{90,91}$, and CLTC, clathrin heavy chain protein, which is integral to synaptic transmission ${ }^{90,92}$. Only ACC layer II/III pyramidal neurons had increased spine density in Btbd3 $\mathrm{KO}$ mice, which might reflect alterations in the hippocampusto-ACC circuit, which is implicated in goal-directed behavior ${ }^{93}$. Indeed, neonatal ventral hippocampal lesions in rodents are thought to disrupt the development of prefrontal circuitry ${ }^{94}$ and enhance mesolimbic dopamine signaling ${ }^{95}$, resulting in extradimensional shifting deficits, hyperactivity, increased apomorphine-induced stereotypy, and reduced rearing, marble-burying, and habituation to novelty ${ }^{96-99}$. This behavioral profile is similar to the phenotype of $B t b d 3 \mathrm{KO}$ and hippocampal Btbd3 KD mice, and aligns with the minimal behavioral effects of dorsal hippocampus-specific Btbd3 KD. While speculative, our results suggest the possibility that loss of BTBD3 primarily in the ventral hippocampus may produce the observed phenotype through disruption of CSTC circuitry.

To our knowledge, our results comprise the first evidence for a role of $B t b d 3$ in behavior, which is to 
modulate compulsive-like and exploratory behaviors in mice. Our results support the possibility that the SNP rs6131295, an eQTL for BTBD3, may be of relevance to neuropsychiatric disorders, despite only exceeding the genome-wide significance threshold in the trio portion of an OCD GWAS ${ }^{13}$. Indeed, OCD patients exhibit compulsive behaviors, goal-directed behavior deficits ${ }^{28-30}$, and reduced novelty-seeking ${ }^{55-58}$. However, other neuropsychiatric disorders exhibit one or more of these phenotypes, including autism spectrum disorder ${ }^{100,101}$, addiction ${ }^{4}$, and binge-eating disorder ${ }^{4}$, suggesting the potential relevance of BTBD3 to other psychiatric disorders. Furthermore, SNPs revealed by GWASs likely lead to subtle changes in gene expression, in comparison to the large reductions in $B t b d 3$ expression studied here in mice. Yet, risk genes for neuropsychiatric disorders identified by GWAS have been suggested to show an increased burden for rare variants with larger damaging effects ${ }^{102,103}$.

Our findings show that reduced Btbd3 expression induces compulsive-like behaviors and reduced exploration, phenotypes highly relevant to neuropsychiatric disorders including OCD. Furthermore, hippocampal Btbd3 expression plays an essential role in the regulation of these behaviors, but loss of BTBD3 in dorsal hippocampus is not sufficient to induce these effects. Future work will determine the molecular mechanisms and developmental time window in which $B t b d 3$ expression confers these phenotypes. As any behavioral role of Btbd3 was previously unreported, our work highlights the importance of investigating unknown genes identified in an unbiased fashion $^{104}$.

\section{Acknowledgements}

The authors would like to thank Dr. Mark Geyer and Richard Sharp for providing Night Owl software for spatial $d$ analysis and assistance with its use. The authors would also like to thank Steven J. Thompson for providing technical assistance. This work was supported by a Brain Research Foundation seed grant (S.C.D.), a NARSAD Independent Investigator award (S.C.D.), R21MH115395-01 (S.C.D.), Della Martin Foundation (J.A.K.), and training grants: T32 GM07839 (S.L.T.), and T32 DA07255 (S.L.T.).

\section{Author details}

'Department of Psychiatry, University of California San Diego, La Jolla, CA 92093, USA. ${ }^{2}$ Committee on Neurobiology, The University of Chicago, Chicago, IL 60637, USA. ${ }^{3}$ Life and Health Sciences Research Institute (ICVS), School of Medicine, University of Minho, Braga, Portugal. ${ }^{4}$ ICVS/3B's - PT Government Associate Laboratory, Braga, Guimarães, Portugal. ${ }^{5}$ Department of Cell Biology, SUNY Downstate Medical Center College of Medicine, Brooklyn, NY 11203, USA

\section{Conflict of interest}

The authors declare that they have no conflict of interest.

\section{Publisher's note}

Springer Nature remains neutral with regard to jurisdictional claims in published maps and institutional affiliations.

Supplementary Information accompanies this paper at (https://doi.org/ 10.1038/s41398-019-0558-7).
Received: 1 May 2019 Accepted: 20 June 2019

Published online: 09 September 2019

\section{References}

1. American Psychiatric Association. Diagnostic and Statistical Manual of Mental Disorders (DSM-5®) (American Psychiatric Publishing, 2013).

2. Brakoulias, V. et al. Comorbidity, age of onset and suicidality in obsessivecompulsive disorder (OCD): an international collaboration. Compr. Psychiatry 76, 79-86 (2017).

3. Gillan, C. M., Kosinski, M., Whelan, R., Phelps, E. A. \& Daw, N. D. Characterizing a psychiatric symptom dimension related to deficits in goal-directed control. elife 5, e11305 (2016).

4. Voon, $\mathrm{V}$. et al. Disorders of compulsivity: a common bias towards learning habits. Mol. Psychiatry 20, 345-352 (2015).

5. Robbins, T. W., Vaghi, M. M. \& Banca, P. Obsessive-compulsive disorder: puzzles and prospects. Neuron 102, 27-47 (2019).

6. Everitt, B. J. \& Robbins, T. W. Neural systems of reinforcement for drug addiction: from actions to habits to compulsion. Nat. Neurosci. 8, 1481-1489 (2005).

7. Gruner, P. \& Pittenger, C. Cognitive inflexibility in obsessive-compulsive disorder. Neuroscience 345, 243-255 (2017).

8. Hollander, E. \& Pallanti, S. Current and experimental therapeutics of OCD. in Neuropsychopharmacology: The Fifth Generation of Progress: an Official Publication of the American College of Neuropsychopharmacology (eds. Davis, K. L., Charney, D. S., Coyle, J. T. \& Nemeroff, C.) 1647-1664 (Lippincott Williams \& Wilkins, 2002).

9. Korff, S., Stein, D. J. \& Harvey, B. H. Stereotypic behaviour in the deer mouse: pharmacological validation and relevance for obsessive compulsive disorder. Prog. Neuropsychopharmacol. Biol. Psychiatry 32, 348-355 (2008).

10. Shanahan, N. A., Velez, L. P., Masten, V. L. \& Dulawa, S. C. Essential role for orbitofrontal serotonin $1 B$ receptors in obsessive-compulsive disorder-like behavior and serotonin reuptake inhibitor response in mice. Biol. Psychiatry 70, 1039-1048 (2011).

11. Shanahan, N. A. et al. Chronic reductions in serotonin transporter function prevent 5-HT1B-induced behavioral effects in mice. Biol. Psychiatry 65, 401-408 (2009).

12. Wolmarans, D. W., Brand, L., Stein, D. J. \& Harvey, B. H. Reappraisal of spontaneous stereotypy in the deer mouse as an animal model of obsessive-compulsive disorder (OCD): response to escitalopram treatment and basal serotonin transporter (SERT) density. Behav. Brain Res. 256, 545-553 (2013).

13. Stewart, S. E. et al. Genome-wide association study of obsessive-compulsive disorder. Mol. Psychiatry 18, 788-798 (2013).

14. Mattheisen, M. et al. Genome-wide association study in obsessivecompulsive disorder: results from the OCGAS. Mol. Psychiatry 20, 337-344 (2015).

15. International Obsessive Compulsive Disorder Foundation Genetics Collaborative (IOCDF-GC) and OCD Collaborative Genetics Association Studies (OCGAS). Revealing the complex genetic architecture of obsessivecompulsive disorder using meta-analysis. Mol. Psychiatry 23, 1181-1188 (2018).

16. Matsui, A. et al. BTBD3 controls dendrite orientation toward active axons in mammalian neocortex. Science 342, 1114-1118 (2013).

17. Lein, E. S. et al. Genome-wide atlas of gene expression in the adult mouse brain. Nature 445, 168-176 (2007).

18. Miller, J. A. et al. Transcriptional landscape of the prenatal human brain. Nature 508, 199-206 (2014)

19. Langen, M., Kas, M. J. H., Staal, W. G., van Engeland, H. \& Durston, S. The neurobiology of repetitive behavior: of mice.... Neurosci. Biobehav. Rev. 35, 345-355 (2011).

20. Langen, M., Durston, S., Kas, M. J. H., van Engeland, H. \& Staal, W. G. The neurobiology of repetitive behavior: ... and men. Neurosci. Biobehav. Rev. 35, 356-365 (2011).

21. Saxena, S. \& Rauch, S. L. Functional neuroimaging and the neuroanatomy of obsessive-compulsive disorder. Psychiatr. Clin. North Am. 23, 563-586 (2000)

22. Lapidus, K. A. B., Stern, E. R., Berlin, H. A. \& Goodman, W. K. Neuromodulation for obsessive-compulsive disorder. Neurotherapentics 11 485-495 (2014). 
23. Bradfield, L. A., Hart, G. \& Balleine, B. W. The role of the anterior, mediodorsal, and parafascicular thalamus in instrumental conditioning. Front. Syst. Neurosci. 7, 51 (2013).

24. Jackson, S. A. W., Horst, N. K., Pears, A., Robbins, T. W. \& Roberts, A. C. Role of the perigenual anterior cingulate and orbitofrontal cortex in contingency learning in the marmoset. Cereb. Cortex N. Y. N. 1991 26, 3273-3284 (2016).

25. van der Meer, M., Kurth-Nelson, Z. \& Redish, A. D. Information processing in decision-making systems. Neurosci. Rev. J. Bringing Neurobiol. Neurol. Psychiatry 18, 342-359 (2012)

26. Miller, K. J., Botvinick, M. M. \& Brody, C. D. Dorsal hippocampus contributes to model-based planning. Nat. Neurosci. 20, 1269-1276 (2017).

27. Parnaudeau, S. et al. Mediodorsal thalamus hypofunction impairs flexible goal-directed behavior. Biol. Psychiatry 77, 445-453 (2015).

28. Gillan, C. M. et al. Disruption in the balance between goal-directed behavior and habit learning in obsessive-compulsive disorder. Am. J. Psychiatry $\mathbf{1 6 8}$ 718-726 (2011).

29. Gillan, C. M. et al. Counterfactual processing of economic action-outcome alternatives in obsessive-compulsive disorder: further evidence of impaired goal-directed behavior. Biol. Psychiatry 75, 639-646 (2014).

30. Gillan, C. M. et al. Functional neuroimaging of avoidance habits in obsessivecompulsive disorder. Am. J. Psychiatry 172, 284-293 (2015).

31. Gillan, C. M. \& Robbins, T. W. Goal-directed learning and obsessive-compulsive disorder. Philos. Trans. R. Soc. B 369, 20130475 (2014)

32. Voon, V., Reiter, A., Sebold, M. \& Groman, S. Model-based control in dimensional psychiatry. Biol. Psychiatry 82, 391-400 (2017).

33. Garner, J. P., Weisker, S. M., Dufour, B. \& Mench, J. A. Barbering (fur and whisker trimming) by laboratory mice as a model of human trichotillomania and obsessive-compulsive spectrum disorders. Comp. Med. 54, 216-224 (2004)

34. Dulawa, S. C., Holick, K. A., Gundersen, B. \& Hen, R. Effects of chronic fluoxetine in animal models of anxiety and depression. Neuropsychopharmacol. Publ. Am. Coll. Neuropsychopharmacol. 29, 1321-1330 (2004).

35. Ho, E. V. et al. Clinically effective OCD treatment prevents 5-HT1B receptorinduced repetitive behavior and striatal activation. Psychopharmacology $\mathbf{2 3 3}$ 57-70 (2016).

36. Abudy, A., Juven-Wetzler, A. \& Zohar, J. Pharmacological management of treatment-resistant obsessive-compulsive disorder. CNS Drugs 25, 585-596 (2011).

37. Leonard, H. L. et al. A double-blind desipramine substitution during longterm clomipramine treatment in children and adolescents with obsessivecompulsive disorder. Arch. Gen. Psychiatry 48, 922-927 (1991).

38. Reinhardt, V. Hair pulling: a review. Lab. Anim. 39, 361-369 (2005).

39. Eagle, D. M., Bari, A. \& Robbins, T. W. The neuropsychopharmacology of action inhibition: cross-species translation of the stop-signal and go/no-go tasks. Psychopharmacology 199, 439-456 (2008).

40. Richardson, N. R. \& Roberts, D. C. Progressive ratio schedules in drug selfadministration studies in rats: a method to evaluate reinforcing efficacy. J. Neurosci. Methods 66, 1-11 (1996).

41. Amitai, N. et al. Isolation rearing effects on probabilistic learning and cognitive flexibility in rats. Cogn. Affect. Behav. Neurosci. 14, 388-406 (2014).

42. Paulus, M. P. \& Geyer, M. A. A temporal and spatial scaling hypothesis for the behavioral effects of psychostimulants. Psychopharmacology 104, 6-16 (1991).

43. Adamah-Biassi, E. B., Hudson, R. L. \& Dubocovich, M. L. Genetic deletion of MT1 melatonin receptors alters spontaneous behavioral rhythms in male and female C57BL/6 mice. Horm. Behav. 66, 619-627 (2014).

44. Deacon, R. M. J. Digging and marble burying in mice: simple methods for in vivo identification of biological impacts. Nat. Protoc. 1, 122-124 (2006).

45. Deacon, R. M. J. \& Rawlins, J. N. P. Hippocampal lesions, species-typical behaviours and anxiety in mice. Behav. Brain Res. 156, 241-249 (2005).

46. Thomas, A. et al. Marble burying reflects a repetitive and perseverative behavior more than novelty-induced anxiety. Psychopharmacology 204 361-373 (2009).

47. de Brouwer, G., Fick, A., Harvey, B. H. \& Wolmarans, D. W. A critical inquiry into marble-burying as a preclinical screening paradigm of relevance for anxiety and obsessive-compulsive disorder: mapping the way forward. Cogn. Affect. Behav. Neurosci. https://doi.org/10.3758/s13415-018-00653-4 (2018).

48. Jirkof, P. Burrowing and nest building behavior as indicators of well-being in mice. J. Neurosci. Methods 234, 139-146 (2014).

49. Deacon, R. M. J. Assessing nest building in mice. Nat. Protoc. 1, 1117-1119 (2006).
50. Misslin, R., Belzung, C. \& Vogel, E. Behavioural validation of a light/dark choice procedure for testing anti-anxiety agents. Behav. Process. 18, 119-132 (1989).

51. Dulawa, S. C. \& Hen, R. Recent advances in animal models of chronic antidepressant effects: the novelty-induced hypophagia test. Neurosci. Biobehav. Rev. 29, 771-783 (2005).

52. Porsolt, R. D., Anton, G., Blavet, N. \& Jalfre, M. Behavioural despair in rats: a new model sensitive to antidepressant treatments. Eur. J. Pharmacol. 47, 379-391 (1978).

53. McDonald, M. P. et al. Hyperactivity and learning deficits in transgenic mice bearing a human mutant thyroid hormone betal receptor gene. Learn. Mem. Cold Spring Harb. N 5, 289-301 (1998).

54. Hill, R. A. et al. Estrogen deficient male mice develop compulsive behavior. Biol. Psychiatry 61, 359-366 (2007).

55. Kusunoki, K. et al. Low novelty-seeking differentiates obsessive-compulsive disorder from major depression. Acta Psychiatr. Scand. 101, 403-405 (2000).

56. Lyoo, I. K., Lee, D. W., Kim, Y. S., Kong, S. W. \& Kwon, J. S. Patterns of temperament and character in subjects with obsessive-compulsive disorder. J. Clin. Psychiatry 62, 637-641 (2001).

57. Kampman, O., Viikki, M., Järventausta, K. \& Leinonen, E. Meta-analysis of anxiety disorders and temperament. Neuropsychobiology 69, 175-186 (2014).

58. Alonso, P. et al. Personality dimensions in obsessive-compulsive disorder: relation to clinical variables. Psychiatry Res. 157, 159-168 (2008).

59. Heller, H. C. et al. Nest building is impaired in the Ts65Dn mouse model of Down syndrome and rescued by blocking 5HT2a receptors. Neurobiol. Learn. Mem. 116, 162-171 (2014).

60. DeLorey, T. M., Sahbaie, P., Hashemi, E., Homanics, G. E. \& Clark, J. D. Gabrb3 gene deficient mice exhibit impaired social and exploratory behaviors, deficits in non-selective attention and hypoplasia of cerebellar vermal lobules: a potential model of autism spectrum disorder. Behav. Brain Res. 187, 207-220 (2008).

61. Carreno-Munoz, M. I. et al. Potential involvement of impaired BKCa channel function in sensory defensiveness and some behavioral disturbances induced by unfamiliar environment in a mouse model of fragile $X$ syndrome. Neuropsychopharmacol. Publ. Am. Coll. Neuropsychopharmacol. 43, 492-502 (2018).

62. Jager, J. et al. Behavioral changes and dopaminergic dysregulation in mice lacking the nuclear receptor Rev-erba. Mol. Endocrinol. 28, 490-498 (2014).

63. Grant, J. E. et al. Trichotillomania and its clinical relationship to depression and anxiety. Int. J. Psychiatry Clin. Pract. 21, 302-306 (2017).

64. Deacon, R. M. J., Croucher, A. \& Rawlins, J. N. P. Hippocampal cytotoxic lesion effects on species-typical behaviours in mice. Behav. Brain Res. 132, 203-213 (2002).

65. Garner, J. P. et al. Reverse-translational biomarker validation of abnormal repetitive behaviors in mice: an illustration of the 4P's modeling approach. Behav. Brain Res. 219, 189-196 (2011).

66. Welch, J. M. et al. Cortico-striatal synaptic defects and OCD-like behaviors in SAPAP3 mutant mice. Nature 448, 894-900 (2007).

67. Chamberlain, S. R., Fineberg, N. A., Blackwell, A. D., Robbins, T. W. \& Sahakian, B. J. Motor inhibition and cognitive flexibility in obsessive-compulsive disorder and trichotillomania. Am. J. Psychiatry 163, 1282-1284 (2006).

68. Nedeljkovic, M. et al. Differences in neuropsychological performance between subtypes of obsessive-compulsive disorder. Aust. N. Z. J. Psychiatry 43, 216-226 (2009).

69. Vaghi, M. M. et al. Specific frontostriatal circuits for impaired cognitive flexibility and goal-directed planning in obsessive-compulsive disorder: evidence from resting-state functional connectivity. Biol. Psychiatry 81, 708-717 (2017)

70. Altemus, M., Glowa, J. R. \& Murphy, D. L. Attenuation of food-restrictioninduced running by chronic fluoxetine treatment. Psychopharmacol. Bull. 29, 397-400 (1993).

71. Altemus, M., Glowa, J. R., Galliven, E., Leong, Y. M. \& Murphy, D. L. Effects of serotonergic agents on food-restriction-induced hyperactivity. Pharmacol. Biochem. Behav. 53, 123-131 (1996)

72. Klenotich, S. J. et al. Olanzapine, but not fluoxetine, treatment increases survival in activity-based anorexia in mice. Neuropsychopharmacol. Publ. Am. Coll. Neuropsychopharmacol. 37, 1620-1631 (2012).

73. Thompson, S. L. \& Dulawa, S. C. Pharmacological and behavioral rodent models of OCD. in Obsessive-Compulsive Disorder: Phenomenology, Pathophysiology, and Treatment (ed. Pittenger, C.) 385-400 (Oxford University Press, 2017). 
74. Gillan, C. M., Otto, A. R., Phelps, E. A. \& Daw, N. D. Model-based learning protects against forming habits. Cogn. Affect. Behav. Neurosci. 15, 523-536 (2015).

75. de Brouwer, G., Fick, A., Harvey, B. H. \& Wolmarans, D. W. A critical inquiry into marble-burying as a preclinical screening paradigm of relevance for anxiety and obsessive-compulsive disorder: mapping the way forward. Cogn. Affect. Behav. Neurosci. https://doi.org/10.3758/s13415-018-00653-4 (2018).

76. Li, X., Morrow, D. \& Witkin, J. M. Decreases in nestlet shredding of mice by serotonin uptake inhibitors: comparison with marble burying. Life Sci. $\mathbf{7 8}$ 1933-1939 (2006).

77. Jaramillo, T. C. et al. Novel Shank3 mutant exhibits behaviors with face validity for autism and altered striatal and hippocampal function. Autism Res. J. Int. Soc. Autism Res. 10, 42-65 (2017).

78. Sungur, A. Ö., Vörckel, K. J., Schwarting, R. K. W. \& Wöhr, M. Repetitive behaviors in the Shank1 knockout mouse model for autism spectrum disorder: developmental aspects and effects of social context. J. Neurosci. Methods 234, 92-100 (2014).

79. Wurzman, R., Forcelli, P. A., Griffey, C. J. \& Kromer, L. F. Repetitive grooming and sensorimotor abnormalities in an ephrin-A knockout model for Autism Spectrum Disorders. Behav. Brain Res. 278, 115-128 (2015).

80. Cohen, J. D., McClure, S. M. \& Yu, A. J. Should I stay or should I go? How the human brain manages the trade-off between exploitation and exploration. Philos. Trans. R. Soc. Lond. B 362, 933-942 (2007).

81. Dulawa, S. C., Grandy, D. K., Low, M. J., Paulus, M. P. \& Geyer, M. A. Dopamine D4 receptor-knock-out mice exhibit reduced exploration of novel stimuli. J. Neurosci. J. Soc. Neurosci. 19, 9550-9556 (1999).

82. Bodnoff, S. R., Suranyi-Cadotte, B., Aitken, D. H., Quirion, R. \& Meaney, M. J. The effects of chronic antidepressant treatment in an animal model of anxiety. Psychopharmacology 95, 298-302 (1988).

83. Bowden, C. L. et al. Fluoxetine and desipramine in major depressive disorder J. Clin. Psychopharmacol. 13, 305-311 (1993).

84. Kleber, R. J. A double-blind comparative study of desipramine hydrochloride and diazepam in the control of mixed anxiety/depression symptomatology. J. Clin. Psychiatry 40, 165-170 (1979).

85. Bandelow, B., Michaelis, S. \& Wedekind, D. Treatment of anxiety disorders. Dialogues Clin. Neurosci. 19, 93-107 (2017).

86. Nagarajan, N., Jones, B. W., West, P. J., Marc, R. E. \& Capecchi, M. R. Corticostriatal circuit defects in Hoxb8 mutant mice. Mol. Psychiatry 23, 1-10 (2018).

87. Shmelkov, S. V. et al. Slitrk5 deficiency impairs corticostriatal circuitry and leads to obsessive-compulsive-like behaviors in mice. Nat. Med. 16, 598-602 (2010). 1p following 602.

88. Consortium, T. B. et al. Analysis of shared heritability in common disorders of the brain. Science 360, eaap8757 (2018).

89. Woehrle, N. S., Klenotich, S. J., Jamnia, N., Ho, E. V. \& Dulawa, S. C. Effects of chronic fluoxetine treatment on serotonin $1 \mathrm{~B}$ receptor-induced deficits in delayed alternation. Psychopharmacology 227, 545-551 (2013).
90. Hein, M. Y. et al. A human interactome in three quantitative dimensions organized by stoichiometries and abundances. Cell 163, 712-723 (2015).

91. Sucic, S. et al. The serotonin transporter is an exclusive client of the coat protein complex II (COPII) component SEC24C. J. Biol. Chem. 286, 16482-16490 (2011).

92. López-Murcia, F. J., Royle, S. J. \& Llobet, A. Presynaptic clathrin levels are a limiting factor for synaptic transmission. J. Neurosci. J. Soc. Neurosci. 34, 8618-8629 (2014).

93. Godsil, B. P., Kiss, J. P., Spedding, M. \& Jay, T. M. The hippocampal-prefrontal pathway: The weak link in psychiatric disorders? Eur. Neuropsychopharmacol. 23, 1165-1181 (2013).

94. Tseng, K. Y., Chambers, R. A. \& Lipska, B. K. The neonatal ventral hippocampal lesion as a heuristic neurodevelopmental model of schizophrenia. Behav. Brain Res. 204, 295-305 (2009).

95. Lipska, B. K. \& Weinberger, D. R. Delayed effects of neonatal hippocampal damage on haloperidol-induced catalepsy and apomorphine-induced stereotypic behaviors in the rat. Brain Res. Dev. Brain Res. 75, 213-222 (1993).

96. Lecourtier, L. et al. Intact neurobehavioral development and dramatic impairments of procedural-like memory following neonatal ventral hippocampal lesion in rats. Neuroscience 207, 110-123 (2012).

97. Ouhaz, Z., Ba-M'hamed, S. \& Bennis, M. Haloperidol treatment at preexposure phase reduces the disturbance of latent inhibition in rats with neonatal ventral hippocampus lesions. C. R. Biol. 337, 561-570 (2014).

98. Marquis, J.-P., Goulet, S. \& Doré, F. Y. Neonatal ventral hippocampus lesions disrupt extra-dimensional shift and alter dendritic spine density in the medial prefrontal cortex of juvenile rats. Neurobiol. Learn. Mem. 90, 339-346 (2008).

99. Daenen, E. W., Van der Heyden, J. A., Kruse, C. G., Wolterink, G. \& Van Ree, J. M. Adaptation and habituation to an open field and responses to various stressful events in animals with neonatal lesions in the amygdala or ventral hippocampus. Brain Res. 918, 153-165 (2001).

100. Alvares, G. A., Balleine, B. W., Whittle, L. \& Guastella, A. J. Reduced goaldirected action control in autism spectrum disorder. Autism Res. J. Int. Soc. Autism Res. 9, 1285-1293 (2016).

101. Vuijk, R., de Nijs, P. F. A., Vitale, S. G., Simons-Sprong, M. \& Hengeveld, M. W. [Personality traits in adults with autism spectrum disorders measured by means of the Temperament and Character Inventory]. Tijdschr. Voor Psychiatr. 54, 699-707 (2012).

102. Sazonovs, A. \& Barrett, J. C. Rare-variant studies to complement genomewide association studies. Annu. Rev. Genomics Hum. Genet. 19, 97-112 (2018).

103. Blair, D. R. et al. A nondegenerate code of deleterious variants in Mendelian loci contributes to complex disease risk. Cell 155, 70-80 (2013).

104. Stoeger, T., Gerlach, M., Morimoto, R. I. \& Amaral, L. A. N. Large-scale investigation of the reasons why potentially important genes are ignored. PLOS Biol. 16, e2006643 (2018). 